\title{
Lymph node dissection for gastric cancer: a critical review
}

\author{
Thales Paulo Batista, ${ }^{1}$ Mário Rino Martins ${ }^{2}$ \\ 'Department of Surgery/Oncology, FPS/IMIP - Faculdade Pernambucana de Saúde, Instituto de \\ Medicina Integral Professor Fernando Figueira; ${ }^{2}$ Department of Surgical Oncology, HCP - Hospital \\ de Câncer de Pernambuco, Brazil
}

\begin{abstract}
Gastric cancer is one of the most common neoplasms and an important cause of cancer-related death worldwide. Efforts to reduce its high mortality rates are currently focused on multidisciplinary management. However, surgery remains a cornerstone in the management of patients with resectable disease. There is still some controversy as to the extent of lymph node dissection for potentially curable stomach cancer. Surgeons in eastern countries favor more extensive lymph node dissection, whereas those in the West favor less extensive dissection. Thus, extent of lymph node dissection remains one of the most hotly discussed aspects of gastric surgery, particularly because most stomach cancers are now often comprehensively treated by adding some perioperative chemotherapy or chemo-radiation. We provide a critical review of lymph nodes dissection for gastric cancer with a particular focus on its benefits in a multimodal approach.
\end{abstract}

\section{Review}

Gastric cancer is one of the most common neoplasms and is a main cause of cancer-related death worldwide, accounting for $8 \%$ of all cases and $10 \%$ of all oncological deaths. ${ }^{1}$ Efforts to reduce its high mortality rates are currently focused on multidisciplinary management. ${ }^{2-7}$ However, surgery remains a cornerstone in the management of

Correspondence: Thales Paulo Batista, Rua Gois Cavalvante, 100, apt.1206 Tamarineira, Recife/PE, 52060-140, Brazil.

Tel. +55.81 .8886 .1203 - Fax: +55.81 .2129 .0151 .

E-mail: t.paulo@bol.com.br

Key words: gastric cancer, lymph node dissection, lymphadenectomy.

Contributions: the authors contributed equally.

Conflict of interests: the authors declare no potential conflict of interests.

Received for publication: 29 February 2012.

Revision received: 29 February 2012.

Accepted for publication: 4 June 2012.

This work is licensed under a Creative Commons Attribution NonCommercial 3.0 License (CC BY-NC 3.0).

(O) Copyright T.P. Batista and M.R. Martins, 2012

Licensee PAGEPress, Italy

Oncology Reviews 2012; 6:e12

doi:10.4081/oncol.2012.e12 patients with resectable disease ${ }^{8-10}$ while the extent of regional lymph node $(\mathrm{N})$ dissection is usually the surgeon's first priority in order to improve outcomes.

There is still some controversy on the optimal surgical resection for potentially curable stomach cancer. In 1999, the first two largest Western randomized trial ${ }^{11,12}$ reported that extended lymph node dissection offers no survival advantage over limited lymphadenectomy, in agreement with previous small trials conducted by Dent et al. ${ }^{13}$ and Robertson et al. ${ }^{14}$ However, extent of lymph node dissection is still the subject of debate. This debate is mainly due to Japanese surgeons who routinely perform more extensive lymphadenectomy, a practice that some suggest at least partially accounts for the better survival rates in Asian than in Western series. ${ }^{15}$

Moreover, in the European Medical Research Council (MRC) and Dutch Gastric Cancer Group (DutchD1D2) trials comparing D1 with $\mathrm{D} 2$ gastrectomy, the mortality rates in patients treated with $\mathrm{D} 2$ gastrectomy reached $10 \%$ or higher. ${ }^{11,12}$ This excessive number of early deaths might have obscured any potential difference in long-term survival between patients undergoing D1 and D2 gastrectomy. ${ }^{16}$ Some critics of the DutchD1D2 trial also comment on the fact that it was conducted in 80 hospitals, including small community hospitals, by 11 surgeons who had had little experience with D2 gastrectomy before the study. ${ }^{17}$ Furthermore, both MRC and the DutchD1D2 studies were relatively underpowered for the group of patients most likely to benefit from extended dissection. If the proportion of patients with $\mathrm{N} 2$ disease is approximately $30 \%$, and only approximately one-fourth of these patients survive five years after a potentially curative D2 lymphadenectomy, less than $8 \%$ of patients benefit long term. These results indicate that one additional life might be saved for every 13 patients undergoing a D2 dissection and that a much larger sample sizes are needed..$^{18}$ Also, even at the time of publication, the possibility that D2 resection without pancreatico-splenectomy may be better than standard D1 resection was highlighted in the MRC trial. ${ }^{12}$

The arguments favoring an extended lymphadenectomy (i.e. D2 or D3 $v s$ D1) are that removing a larger number of nodes more accurately stages disease extent and that failure to remove these nodes leaves behind disease (which would be a potentially fatal event) in as many as one-third of patients. ${ }^{18} \mathrm{~A}$ consequence of more accurate staging is to minimize stage migration (the Okie phenomenon, as described by Will Rodgers). The resulting improvement in stage-specific survival may explain, in part, the better results in Asian patients..$^{19}$ Furthermore, the influence of total lymph node count on stage-specific survival has been extensively studied and also proved to be significantly better as more nodes were examined in every stage subgroup. ${ }^{20}$

Similarly, interesting findings may also be observed when surgicalonly arms of the main trials that guide the current multidisciplinary treatment of gastric cancer are compared. For example, 3-year overall survival in the INT 0116 trial, ${ }^{3}$ Japanese ACTS-GC Trial ${ }^{21}$ and Korean CLASSIC trial ${ }^{4}$ were $41 \%, 70 \%$ and $78 \%$, respectively. In the former, only $10 \%$ of patients included in the analysis had undergone a formal 
D2 dissection. A D1 dissection had been performed in $36 \%$, but most patients (54\%) had undergone a D0 dissection, which is less than a complete dissection of the N1 nodes. On the contrary, almost all patients underwent a D2-type gastrectomy in the ACTS-GC and CLASSIC trials. Equally, 5-year overall survival of surgery-only arms from the MAGIC, ${ }^{2}$ ACCORD $07-F F C D ~ 9703^{5}$ and ACTS-GC ${ }^{6}$ trials were $23 \%, 24 \%$ and $61 \%$, respectively, with clearly better survival rates in this last trial. Obviously, to compare eastern versus western experiences may not be appropriate but if we explore results of the European EORTC 40954 trial $^{22}$ which closed early and in which a D2 dissection was achieved in $92.6 \%$ of patients, 2-year survival was approximately $70 \%$ in the surgery-only arm, suggesting some benefit from D2 lymphadenectomy also to western patients. These best survival rates favoring a more extensive lymph node dissection are possibly linked to the lower recurrence rates observed in those trials in which a D2-dissection was standard (Table 1).

From 1999 to 2010, a review of the DutchD1D2 trial data came to some divergent conclusions. In 1999, the first analysis of these data did not support the routine use of D2 lymph-node dissection in patients with gastric cancer based on 5-year survival rates that were similar between D1 versus D2 dissection; $45 \%$ versus $47 \%$, respectively. ${ }^{11}$ In 2004, Hartgrink et al. ${ }^{16}$ reviewed results of this trial after a follow up of more than ten years and concluded that associated higher postoperative mortality offsets its long-term effect on survival. In this study, the authors reported that an extended lymph node dissection may offer a cure for patients with N2 disease, suggesting D2 lymph node dissections may add some benefit if morbidity and mortality can be avoided. Recently, these data were updated again after a median follow up of 15.2 years (range 6.9-17.9 years). Accordingly, D2 lymphadenectomy was associated with lower locoregional recurrence and gastric cancer related death rates rather than D1 surgery. ${ }^{23}$

A Brazilian meta-analyze of randomized controlled trials conducted by Lustosa et al. ${ }^{24}$ confirmed that D2 lymphadenectomy procedure is followed by a lower incidence of recurrence and mortality with recurrent disease. In spite of this, D2 procedure did not make a significant impact on 5-year survival in this review. According to this study, D2 lymphadenectomy procedure was also associated with higher overall morbidity and higher in-hospital mortality. On the basis of another meta-analysis, Memon et al. ${ }^{25}$ also reported that D1 gastrectomy is associated with significant fewer morbidity and 30-day mortality rate with similar 5-year survival to the D2-type procedure.

In a very recent systematic review from the Cochrane Database, ${ }^{26}$ McCulloch and colleagues concluded that D2 dissection carries increased mortality risks associated with spleen and pancreas resection, and probably also associated with operator inexperience and low case volumes. In this analysis, the authors reported that randomized studies show no evidence of overall survival benefit but they do show possible benefit in T3+ tumors. These results may be confounded by surgical learning curves and poor surgeon compliance. On the other hand, they also pointed out that non-randomized comparisons suggest a possible survival benefit in intermediate TNM Union for International Cancer Control (UICC) stages. In addition, observational studies show high 5-year survival and low operative mortality after D2 dissection in experienced units, and poor results after D1 dissection in non-specialist units. ${ }^{26}$

In the last DutchD1D2 trail review, Songun et al. ${ }^{23}$ similarly observed that D2 procedure was associated with significantly higher postoperative mortality and morbidity rates, and higher rates of further surgery, confirming its previous findings. ${ }^{11}$ Nevertheless, many of the patients included in these studies underwent some pancreatic and/or spleen resection as part of D2 dissection and nowadays, because a safer spleen-preserving D2 resection technique is currently available in high-volume centers, D2 lymphadenectomy should be the recommended surgical approach for patients with resectable (curable) gastric cancer. $^{23}$ Outcomes of main trials comparing a limited (D1) versus an extended (D2 or D3) lymphadenectomy are shown in Table 2.

Table 1. Recurrence rates among those patients who underwent surgical resection alone in the main trials that guide the current multidisciplinary treatment of gastric cancer.

\begin{tabular}{|c|c|c|c|c|c|}
\hline & INT $0116^{3}$ & MAGIC $^{2}$ & $\begin{array}{l}\text { Clinical Trials } \\
\text { ACCORD }^{*}\end{array}$ & ACTS-GC 6,21 & CLASSIC 4 \\
\hline $\mathrm{n}$ & 275 & 253 & 111 & 530 & 515 \\
\hline Median follow up & 5 years & 4.1 years & 5.7 years & 5 years & 2.9 year \\
\hline Overall recurrence & $177(64.3 \%)$ & $190(75.1 \%)$ & $71(64 \%)$ & $221(41.7 \%)$ & $155(30.1 \%)$ \\
\hline Pattern of recurrence & $\begin{array}{c}\text { Local - } 51(18.5 \%) \\
\text { Regional }^{\circ}-127(46.1 \%) \\
\text { Distant - }^{\circ} 2(11.6 \%)\end{array}$ & $\begin{array}{c}\text { Local - } 52(20.6 \%) \\
- \\
\text { Distant - } 93(36.8 \%)\end{array}$ & $\begin{array}{c}\text { Loco-regional - } 9(8 \%) \\
\text { Both - } 20(18 \%) \\
\text { Distant - } 42(38 \%)\end{array}$ & $\begin{array}{c}\text { Loco-regional }^{\#} \text { - } 71(13.4 \%) \\
\text { Peritoneum - } 100(18.9 \%) \\
\text { Distant - } 71(13.4 \%)\end{array}$ & $\begin{array}{c}\text { Loco-regional - } 44(8.5 \%) \\
\text { Peritoneum - } 56(10.9 \%) \\
\text { Distant - } 78(15.1 \%)\end{array}$ \\
\hline Disease-free survival & $31 \%$ (3-year) & & $19 \%$ (5-year) & $59.6 \%$ (3-year)/53.1\% (5-year) & $59 \%$ (3-year) \\
\hline
\end{tabular}

"Patients randomly assigned to surgical resection alone; ${ }^{\circ}$ Typically, abdominal carcinomatosis; "Local: 17 (3.2\%) and lymph nodes: 54 (10.2\%).

Table 2. The largest randomized clinical trials comparing limited versus extended lymphadenectomy.

\begin{tabular}{|c|c|c|c|c|c|}
\hline Randomized trial & Country & Intervention & Operative morbidity & Operative mortality & 5-year survival \\
\hline Dutch $^{11,16,23}$ & Netherlands & $\begin{array}{l}\text { D1 }(\mathrm{n}=380) \\
\text { D2 }(\mathrm{n}=331)\end{array}$ & $\begin{array}{l}25 \% \\
43 \%\end{array}$ & $\begin{array}{l}4 \% \\
10 \%\end{array}$ & $\begin{array}{l}45 \% \\
47 \%\end{array}$ \\
\hline $\mathrm{MRC}^{12,27}$ & UK & $\begin{array}{l}\text { D1 }(\mathrm{n}=200) \\
\text { D2 }(\mathrm{n}=200)\end{array}$ & $\begin{array}{l}28 \% \\
46 \%\end{array}$ & $\begin{array}{l}6.5 \% \\
13 \%\end{array}$ & $\begin{array}{l}35 \% \\
33 \%\end{array}$ \\
\hline Taiwanese $\mathrm{e}^{28,29}$ & Taiwan & $\begin{array}{l}\text { D1 }(n=110) \\
\text { D3 }(n=111)\end{array}$ & $\begin{array}{c}7.3 \% \\
17.1 \%\end{array}$ & $\begin{array}{l}0 \% \\
0 \%\end{array}$ & $\begin{array}{l}53.6 \% \\
59.5 \%\end{array}$ \\
\hline $\operatorname{IGCSG}^{30,31}$ & Italy & $\begin{array}{l}\text { D1 }(\mathrm{n}=133) \\
\text { D2 }(\mathrm{n}=134)\end{array}$ & $\begin{array}{c}12 \% \\
17.9 \%\end{array}$ & $\begin{array}{c}3 \% \\
2.2 \%\end{array}$ & - \\
\hline
\end{tabular}

MRC, Medical Research Council; IGCSG, Italian Gastric Cancer Study Group. 
In 2004, Degiuli et al. ${ }^{30}$ had also shown morbidity and mortality after extended gastrectomy may have been as low as those reported by Japanese authors in very experienced centers. At that time, these authors suggested D2 gastrectomies with pancreas preservation were not followed by significantly higher morbidity and mortality than D1 resections. These data were updated in 2010 , confirming that the rate of complications following D2 dissection is much lower than that published in previous randomized western trials. ${ }^{31} \mathrm{D} 2$ dissection was, therefore, considered a safe option for the radical management of gastric cancer in an appropriate setting ${ }^{31}$ and became the recommended surgery approach for advanced resectable gastric cancer in Europe. ${ }^{32}$

Results of two randomized controlled trials do not support the use of prophylactic splenectomy to remove macroscopically negative lymph nodes near the spleen in patients undergoing total gastrectomy for proximal gastric cancer or in early stages of disease. ${ }^{33,34}$ In the Japan Clinical Oncology Group (JCOG) 9501 study, pancreas-preserving splenectomy was generally performed with low surgical mortality. In this study, only 22 of 523 patients underwent pancreaticosplenectomy and $59 \%$ of them (13 of 22 cases) developed postoperative complications. ${ }^{17,35}$ According to Yao and colleagues ${ }^{36}{ }^{5}$-year survival rates of patients underwent spleen-preserving versus splenectomy D2-gastrectomy are usually very similar, ranging from approximately $100 \%$ to $100 \%$ for stage I, $66.7 \%$ versus $70.0 \%$ for stage II, $27.8 \%$ versus $26.7 \%$ for stage III, and $17.4 \%$ versus $5.6 \%$ for stage IV, respectively; none of these differences were statistically significant. Furthermore, there is a significant difference in postoperative morbidity rate (11.5\% vs $27.5 \%)$ favoring spleen-preserving D2-gastrectomy.

On the other hand, total gastrectomy with splenectomy has still been recommended for patients with T3 proximal gastric cancer who have 10-station lymph node metastasis to improve their prognosis. ${ }^{37}$ Similarly, the current Japanese gastric cancer treatment guidelines continues to include splenectomies as part of the definition of D2 lymphadenectomies in more than $\mathrm{T} 2$ proximal third tumors eligible for a total gastrectomy. ${ }^{8}$ However, preliminary results of the ongoing JCOG 0110 trial confirmed greater blood loss and operative morbidity in the group who underwent splenectomies. ${ }^{38}$ Final results from this trial will allow us to establish definitively whether splenectomies can be avoided without compromising patient survival in cases involving proximal tumors. ${ }^{39}$ For now, two recent meta-analysis have confirmed that preservation of the spleen and pancreas during extended lymphadenectomy for gastric cancer decreases complication rates and therefore, routine splenectomy and/or pancreatectomy should not be recommended because it has not been shown to have any beneficial effect on patient survival..$^{40,41}$

Asian surgeons have also proposed a more radical lymph node dissection in order to improve survival for patients with stage T2-4 tumors. In this extensive procedure, designated as D4 dissection, paraaortic lymph nodes are removed in combination with D2 dissection. Two Japanese trials rigorously explored this important issue ${ }^{17,42}$ and concluded that treatment with D2 lymphadenectomy plus paraaor- tic lymph node dissection (PAND) does not improve the survival rate in curable gastric cancer when compared with standard D2 lymphadenectomy alone. Thus, systematic D4 dissection has not been recommended for treatment of stomach cancer because it failed to benefit overall survival in patients with potentially curable advanced gastric cancer. ${ }^{17,42-44}$ Furthermore, although an extended dissection may be performed as safely as D2 dissection when performed by well-trained surgeons ${ }^{43-46}$ and obviously offers a survival benefit for patients with gastric cancer when compared to D1 dissection, ${ }^{28}$ this extended lymphadenectomy is often significantly associated with higher surgical complication rates. ${ }^{29,35,45}$ Some of these trials comparing D2 and D2 plus PAND are summarized in Table 3.

Recently, the Union for International Cancer Control (UICC)/ American Joint Committee on Cancer (AJCC) and the Japanese Gastric Cancer Association (JGCA) have put a great deal of effort into working together and establishing a common language to express the clinical experience and results from around the world. Accordingly, the new $\mathrm{pN}$ categories and the new definitions of types of lymphadenectomies attempt to simplify and standardize the surgical management of gastric cancer taking into account the type of gastrectomy to be performed. ${ }^{47}$ Therefore, a D1 lymphadenectomy has been referred to a limited dissection of only the perigastric lymph nodes whereas the D2 lymphadenectomy is an extended lymph node dissection, involving removal of nodes along the hepatic, left gastric, celiac and splenic arteries as well as those in the splenic hilum (stations 1-11). Similarly, the D3 dissection comprises the superextended lymphadenectomy, a term that has been used by some to describe a D2 lymphadenectomy plus the removal of nodes within the porta hepatis and periaortic regions (stations 1-16), while others use the term to denote a D2 lymphadenectomy plus periaortic nodal dissection (PAND) alone. Most western surgeons (and the UICC/AJCC TNM staging classification) classify disease in these regions as distant metastases and do not routinely remove nodes in these areas during a potentially curative gastrectomy. ${ }^{17}$ Nowadays, in both eastern and western countries, D2 lymph node dissections have been considered a more appropriate procedure at highvolume centers or for skilled surgeons, and this is recommended by most current gastric cancer guidelines for resectable disease. ${ }^{8-10}$ Japanese surgeons meticulously divided the draining lymph node basins for the stomach into 16 stations. The principal lymph nodes of these stations, as provided by the Japanese Research Society for Gastric Cancer, are shown in Figure 1.

The potential benefit from extended lymphadenectomy in patients with gastric cancer has been the subject of considerable debate. ${ }^{48}$ Surgeons in eastern countries favor more extensive lymph node dissection, whereas those in western countries favor less extensive dissection. Therefore, extent of lymph node dissection remains one of the most hotly discussed aspects of gastric surgery. However, in order to improve outcomes, the decision between D1 versus D2 lymph node dissection should be personalized after consideration of patient characteristics, tumor stage and surgical experience, especially because stom-

Table 3. The largest randomized clinical trials comparing standard D2-dissection versus extended D2 plus PAND dissection.

\begin{tabular}{|c|c|c|c|c|c|}
\hline Randomized trial & Country & Intervention & Operative morbidity & Operative mortality & 5-year survival \\
\hline $\mathrm{JCOG}^{17,35}$ & Japan & $\begin{array}{c}\text { D2 }(\mathrm{n}=264) \\
\text { D2 plus PAND* }(\mathrm{n}=260)\end{array}$ & $\begin{array}{l}20.9 \% \\
28.1 \%\end{array}$ & $\begin{array}{l}0.8 \% \\
0.8 \%\end{array}$ & $\begin{array}{l}69.2 \% \\
70.3 \%\end{array}$ \\
\hline Polish $^{46}$ & Poland & $\begin{array}{c}\text { D2 }(\mathrm{n}=141) \\
\text { D2 plus PAND }(\mathrm{n}=134)\end{array}$ & $\begin{array}{l}27.7 \% \\
21.6 \%\end{array}$ & $\begin{array}{l}4.9 \% \\
2.2 \%\end{array}$ & - \\
\hline East Asian ${ }^{42,45}$ & Multicenter ${ }^{\circ}$ & $\begin{array}{c}\text { D2 }(\mathrm{n}=135) \\
\text { D2 plus PAND }(\mathrm{n}=134)\end{array}$ & $\begin{array}{l}26 \% \\
39 \%\end{array}$ & $\begin{array}{l}0.7 \% \\
3.7 \%\end{array}$ & $\begin{array}{l}52.6 \% \\
55.4 \%\end{array}$ \\
\hline
\end{tabular}

JCOG, Japan Clinical Oncology Group. *Paraaortic lymph node dissection; 'Japan, Korea, and Chinese Taiwan area. 
ach cancers are now often comprehensively treated by a multimodal approach including perioperative chemotherapy or chemo-radiation. So, an aggressive nodal dissection should only be performed in selected centers where surgeons have demonstrated acceptably low operative morbidity and mortality rates with expected mortality rates of less than $2 \%$. Besides, taking into account promising advances in these therapeutic options (including, for example, target therapy), the benefit of an extensive dissection may ultimately become more limited if some highly effective perioperative therapies are available. Whether these therapies may replace more extensive surgical procedure (possibly at a much higher cost), or if their benefit would also be extended to more extensive surgery remains unclear. ${ }^{48}$

At the moment, current data have favored the adoption of some adjuvant therapy even after a D2-dissection. ${ }^{4,6,7,49}$ For instance, the CLASSIC trial ${ }^{4}$ has demonstrated improved 3 -year overall and disease-free survival ( $83 \%$ and $74 \%$, respectively) by adding adjuvant oxaliplatin and capecitabine to D2-gastrectomy. Similarly, the ARTIST trial ${ }^{7}$ reported 3year disease-free survival of $74.2 \%$ for D2-gastrectomy plus adjuvant capecitabine/cisplatin-based chemotherapy. Previously, the Japanese ACTS-GC trial had also confirmed that oral fluoropyrimidine derivative S-1 significantly improved overall survival. ${ }^{6,21}$ On the other hand, the ARTIST trial ${ }^{7}$ failed to demonstrate any advantage from adding radiation to adjuvant chemotherapy after a D2-dissection, as previously questioned in a similar study conducted by Kwon et al. ${ }^{50}$ According to Lee and colleagues, ${ }^{7}$ some improvement was seen only in the lymph node-positve subgroup, but this needs to be interpreted with caution after a longer follow up or/and after a subsequent phase III trial (ARTIST-II) planned to confirm the benefit of adjuvant chemo-radiation for patients with D2 lymph node dissection and pathological lymph

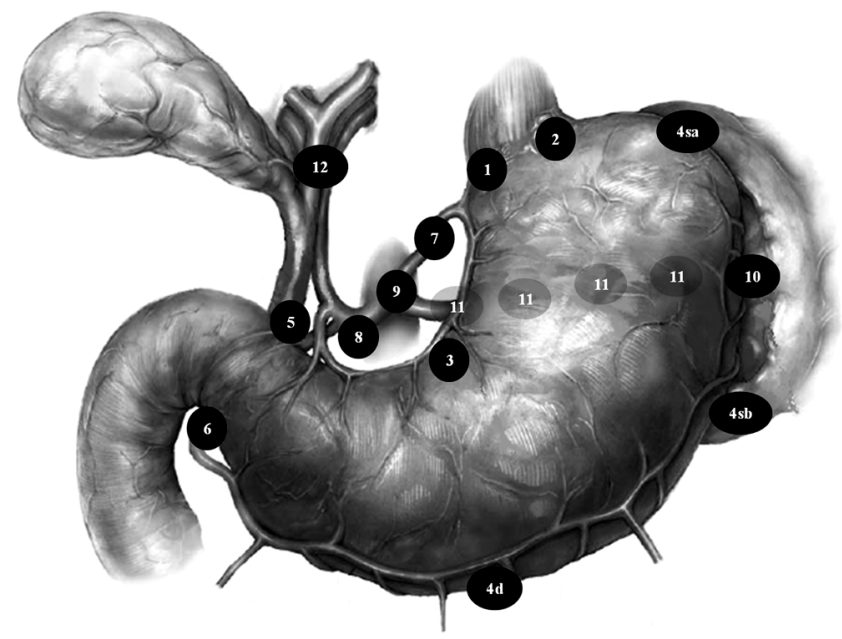

Figure 1. Lymph node stations as defined by the Japanese Research Society for Gastric Cancer. (1) Right and (2) left cardial nodes; along the (3) lesser and (4) greater curvature; (5) suprapyloric and (6) infrapyloric nodes; (7) along the left gastric artery; (8) along the common hepatic artery; (9) around the celiac axis; (10) at the splenic hilum; (11) along the splenic artery; (12) nodes in the hepatoduodenal ligament. According to current Japanese gastric cancer treatment guidelines 2010, 8 a D1-gastrectomy requires dissection of nodal stations 1-7 for total gastrectomy or $1,3,4 \mathrm{sb}, 4 \mathrm{~d}, 5,6$ and 7 for distal gastrectomy. D1(+) dissection adds stations $8 \mathrm{a}, 9$ and $11 \mathrm{p}$ or $8 \mathrm{a}$ and 9 respectively. D2 lymphadenectomy includes nodal stations dissected in D1 plus 8a, 9, $10,11 \mathrm{p}, 11 \mathrm{~d}$ and 12a stations (total gastrectomy) or $8 \mathrm{a}, 9,11 \mathrm{p}$ and 12 a nodal stations (distal gastrectomy). node-positive disease.

Finally, it should be emphasized that lymph node dissection proved to be a main factor in the spread of viable free cancer cells into the peritoneal cavity and itself appears to play a role in peritoneal dissemination of gastric cancer. ${ }^{51}$ Exploring the mechanisms of peritoneal recurrence in gastric cancer by an ultra-rapid quantitative real-time polymerase chain reaction system, Marutsuka and colleagues ${ }^{51}$ clearly revealed the existence of free cancer cells in the peritoneal cavity after lymphadenectomy, even when the gastric serosa was not disrupted. Accordingly, this very important observation may explain the high rates of peritoneal recurrence after curative operations, despite neither the apparent existence of abdominal free cancer cells nor overt peritoneal metastasis before surgery. Fortunately, these authors also developed a quite formidable method for reducing the number of free cancer cells to potentially zero, namely by extensive intraoperative peritoneal lavage (EIPL). ${ }^{51,52}$ Based on their pioneering studies, the results far exceeded any expectations and showed a remarkably better prognosis for patients with gastric cancer, ${ }^{52,53}$ these authors have strongly advocated the adoption of EIPL therapy as a standard prophylactic strategy for peritoneal dissemination in advanced gastric cancer. ${ }^{53,54}$ Furthermore, adjuvant intraperitoneal plus intravenous chemotherapy offers no clear benefit in terms of overall and relapse-free survival after curative resection in serosa-positive gastric cancer, ${ }^{55}$ but the peritoneal free cancer cell volume appears to have a strong impact on the outcome of patients with positive peritoneal lavage cytology and negative macroscopic peritoneal implant, ${ }^{56}$ a mechanical method to reduce the cancer cell population into the peritoneal cavity (i.e. EIPL) may probably improve patient survival rates in either serosa- or lymph nodepositive gastric cancer patients undergoing D2-gastrectomy.

\section{References}

1. Jemal A, Bray F, Center MM, et al. Global cancer statistics. CA Cancer J Clin 2011;61:69-90.

2. Cunningham D, Allum WH, Stenning SP, et al. Perioperative chemotherapy versus surgery alone for resectable gastroesophageal cancer. N Engl J Med 2006;355:11-20.

3. Macdonald JS, Smalley SR, Benedetti J, et al. Chemoradiotherapy after surgery compared with surgery alone for adenocarcinoma of the stomach or gastroesophageal junction. N Engl J Med 2001;345: $725-30$.

4. Bang YJ, Kim YW, Yang HK, et al. Adjuvant capecitabine and oxaliplatin for gastric cancer after D2 gastrectomy (CLASSIC): a phase 3 open-label, randomised controlled trial. Lancet 2012 Jan 6. [Epub ahead of print].

5. Ychou M, Boige V, Pignon JP, et al. Perioperative chemotherapy compared with surgery alone for resectable gastroesophageal adenocarcinoma: an FNCLCC and FFCD multicenter phase III trial. J Clin Oncol 2011;29:1715-21.

6. Sasako M, Sakuramoto S, Katai H, et al. Five-year outcomes of a randomized phase III trial comparing adjuvant chemotherapy with S-1 versus surgery alone in stage II or III gastric cancer. J Clin Oncol 2011;29:4387-93.

7. Lee J, Lim do H, Kim S, et al. Phase III Trial comparing capecitabine plus cisplatin versus capecitabine plus cisplatin with concurrent capecitabine radiotherapy in completely resected gastric cancer with D2 lymph node dissection: The ARTIST Trial. J Clin Oncol 2012;30: 268-73.

8. Japanese Gastric Cancer Association. Japanese gastric cancer treatment guidelines 2010 (ver. 3). Gastric Cancer 2011;14:113-23.

9. Okines A, Verheij M, Allum W, et al. Gastric cancer: ESMO Clinical 
Practice Guidelines for diagnosis, treatment and follow-up. Ann Oncol 2010;21 Suppl 5:v50-4.

10. NCCN. NCCN Clinical Practice Guidelines in Oncology. Gastric Cancer. Version 2.2011. 2011. http://www.nccn.org Accessed: December 5, 2011.

11. Bonenkamp JJ, Hermans J, Sasako M, et al. Extended lymph-node dissection for gastric cancer. N Engl J Med 1999;340:908-14.

12. Cuschieri A, Weeden S, Fielding J, et al. Patient survival after D1 and D2 resections for gastric cancer: long-term results of the MRC randomized surgical trial. Surgical Co-operative Group. Br J Cancer 1999;79:1522-30.

13. Dent DM, Madden MV, Price SK. Randomized comparison of R1 and R2 gastrectomy for gastric carcinoma. Br J Surg 1988;75:110-2.

14. Robertson CS, Chung SC, Woods SD, et al. A prospective randomized trial comparing R1 subtotal gastrectomy with R3 total gastrectomy for antral cancer. Ann Surg 1994;220:176-82.

15. Noguchi Y, Yoshikawa T, Tsuburaya A, et al. Is gastric carcinoma different between Japan and the United States? Cancer 2000;89: 2237-46.

16. Hartgrink HH, van de Velde CJ, Putter H, et al. Extended lymph node dissection for gastric cancer: who may benefit? Final results of the randomized Dutch gastric cancer group trial. J Clin Oncol 2004;22:2069-77.

17. Sasako M, Sano T, Yamamoto S, et al. D2 lymphadenectomy alone or with para-aortic nodal dissection for gastric cancer. N Engl J Med 2008;359:453-62.

18. Roukos DH, Kappas AM. Targeting the optimal extent of lymph node dissection for gastric cancer. J Surg Oncol 2002;81:59-62.

19. de Manzoni G, Verlato G, Roviello F, et al. The new TNM classification of lymph node metastasis minimises stage migration problems in gastric cancer patients. Br J Cancer 2002;87:171-4.

20. Smith DD, Schwarz RR, Schwarz RE. Impact of total lymph node count on staging and survival after gastrectomy for gastric cancer: data from a large US-population database. J Clin Oncol 2005;23:7114-24.

21. Sakuramoto S, Sasako M, Yamaguchi T, et al. Adjuvant chemotherapy for gastric cancer with S-1, an oral fluoropyrimidine. N Engl J Med 2007;357:1810-20.

22. Schuhmacher C, Gretschel S, Lordick F, et al. Neoadjuvant chemotherapy compared with surgery alone for locally advanced cancer of the stomach and cardia: European Organisation for Research and Treatment of Cancer randomized trial 40954. J Clin Oncol 2010;28:5210-8.

23. Songun I, Putter H, Kranenbarg EM, et al. Surgical treatment of gastric cancer: 15-year follow-up results of the randomised nationwide Dutch D1D2 trial. Lancet Oncol 2010;11:439-49.

24. Lustosa SA, Saconato H, Atallah AN, et al. Impact of extended lymphadenectomy on morbidity, mortality, recurrence and 5-year survival after gastrectomy for cancer. Meta-analysis of randomized clinical trials. Acta Cir Bras 2008;23:520-30.

25. Memon MA, Subramanya MS, Khan S, et al. Meta-analysis of D1 versus D2 gastrectomy for gastric adenocarcinoma. Ann Surg 2011;253:900-11.

26. McCulloch P, Nita ME, Kazi H, Gama-Rodrigues JJ. WITHDRAWN: Extended versus limited lymph nodes dissection technique for adenocarcinoma of the stomach. Cochrane Database Syst Rev 2012;1:CD001964.

27. Cuschieri A, Fayers P, Fielding J, et al. Postoperative morbidity and mortality after D1 and D2 resections for gastric cancer: preliminary results of the MRC randomised controlled surgical trial. The Surgical Cooperative Group. Lancet 1996;347:995-9.

28. Wu CW, Hsiung CA, Lo SS, et al. Nodal dissection for patients with gastric cancer: a randomised controlled trial. Lancet Oncol 2006;7:309-15.
29. Wu CW, Hsiung CA, Lo SS, et al. Randomized clinical trial of morbidity after D1 and D3 surgery for gastric cancer. Br J Surg. 2004;91:283-7.

30. Degiuli M, Sasako M, Calgaro M, et al. Morbidity and mortality after D1 and D2 gastrectomy for cancer: interim analysis of the Italian Gastric Cancer Study Group (IGCSG) randomised surgical trial. Eur J Surg Oncol 2004;30:303-8.

31. Degiuli M, Sasako M, Ponti A, Italian Gastric Cancer Study Group. Morbidity and mortality in the Italian Gastric Cancer Study Group randomized clinical trial of D1 versus D2 resection for gastric cancer. Br J Surg 2010;97:643-9.

32. Dikken JL, Verheij M, Cats A, et al. Extended lymph node dissection for gastric cancer from a European perspective. Gastric Cancer 2011;14:396-8.

33. Yu W, Choi GS, Chung HY. Randomized clinical trial of splenectomy versus splenic preservation in patients with proximal gastric cancer. Br J Surg 2006;93:559-63.

34. Csendes A, Burdiles P, Rojas J, et al. A prospective randomized study comparing D2 total gastrectomy versus $\mathrm{D} 2$ total gastrectomy plus splenectomy in 187 patients with gastric carcinoma. Surgery 2002;131:401-7.

35. Sano T, Sasako M, Yamamoto S, et al. Gastric cancer surgery: morbidity and mortality results from a prospective randomized controlled trial comparing D2 and extended para-aortic lymphadenectomy--Japan Clinical Oncology Group study 9501. J Clin Oncol 2004;22:2767-73.

36. Yao XX, Sah BK, Yan M, et al. Radical gastrectomy with combined splenectomy: unnecessary. Hepatogastroenterology 2011;58:106770.

37. Huang CM, Wang JB, Lu HS, et al. Prognostic impact of splenectomy on advanced proximal gastric cancer with No. 10 lymph node metastasis. Chin Med J (Engl) 2009;122:2757-62.

38. Sano T, Sasako M, Shibata T, et al. Randomized controlled trial to evaluate splenectomy in total gastrectomy for proximal gastric carcinoma (JCOG0110): Analyzes of operative morbidity, operation time and bood loss. J Clin Oncol 2010;28:15s. (Suppl; abstr: 4020).

39. Sano T, Yamamoto S, Sasako M, Japan Clinical Oncology Group Study LCOG 0110-MF. Randomized controlled trial to evaluate splenectomy in total gastrectomy for proximal gastric carcinoma: Japan clinical oncology group study JCOG 0110-MF. Jpn J Clin Oncol 2002;32:363-4.

40. Yang K, Chen XZ, Hu JK, et al. Effectiveness and safety of splenectomy for gastric carcinoma: a meta-analysis. World J Gastroenterol 2009;15:5352-9.

41. Brar SS, Seevaratnam R, Cardoso R, et al. A systematic review of spleen and pancreas preservation in extended lymphadenectomy for gastric cancer. Gastric Cancer 2011 Sep 14. [Epub ahead of print].

42. Yonemura Y, Wu CC, Fukushima N, et al. Randomized clinical trial of D2 and extended paraaortic lymphadenectomy in patients with gastric cancer. Int J Clin Oncol 2008;13:132-7.

43. Wang Z, Chen JQ, Cao YF. Systematic review of D2 lymphadenectomy versus $\mathrm{D} 2$ with para-aortic nodal dissection for advanced gastric cancer. World J Gastroenterol 2010;16:1138-49.

44. Chen XZ, Hu JK, Zhou ZG, et al. Meta-analysis of effectiveness and safety of D2 plus para-aortic lymphadenectomy for resectable gastric cancer. J Am Coll Surg 2010;210:100-5.

45. Yonemura Y, Wu CC, Fukushima N, et al. Operative morbidity and mortality after D2 and D4 extended dissection for advanced gastric cancer: a prospective randomized trial conducted by Asian surgeons. Hepatogastroenterology 2006;53:389-94.

46. Kulig J, Popiela T, Kolodziejczyk P, et al. Standard D2 versus extended D2 (D2+) lymphadenectomy for gastric cancer: an interim safety analysis of a multicenter, randomized, clinical trial. Am J Surg 
2007;193:10-5.

47. Santiago JM, Sasako M, Osorio J. [TNM-7th edition 2009 (UICC/AJCC) and Japanese Classification 2010 in Gastric Cancer. Towards simplicity and standardisation in the management of gastric cancer]. Cir Esp 2011;89:275-81.

48. Mansfield PF. Lymphadenectomy for gastric cancer. J Clin Oncol 2004;22:2759-61.

49. Kim S, Lim DH, Lee J, et al. An observational study suggesting clinical benefit for adjuvant postoperative chemoradiation in a population of over 500 cases after gastric resection with D2 nodal dissection for adenocarcinoma of the stomach. Int J Radiat Oncol Biol Phys 2005;63:1279-85.

50. Kwon HC, Kim MC, Kim KH, et al. Adjuvant chemoradiation versus chemotherapy in completely resected advanced gastric cancer with D2 nodal dissection. Asia Pac J Clin Oncol 2010;6:278-85.

51. Marutsuka T, Shimada S, Shiomori K, et al. Mechanisms of peritoneal metastasis after operation for non-serosa-invasive gastric carcinoma: an ultrarapid detection system for intraperitoneal free cancer cells and a prophylactic strategy for peritoneal metastasis. Clin Cancer Res 2003;9:678-85.
52. Shimada S, Tanaka E, Marutsuka T, et al. Extensive intraoperative peritoneal lavage and chemotherapy for gastric cancer patients with peritoneal free cancer cells. Gastric Cancer 2002;5:168-72.

53. Kuramoto M, Shimada S, Ikeshima $S$, et al. Extensive intraoperative peritoneal lavage as a standard prophylactic strategy for peritoneal recurrence in patients with gastric carcinoma. Ann Surg 2009;250:242-6.

54. Shimada S, Kuramoto M, Marutsuka T, et al. Adopting extensive intra-operative peritoneal lavage (EIPL) as the standard prophylactic strategy for peritoneal recurrence. Rev Recent Clin Trials 2011;6:266-70.

55. Miyashiro I, Furukawa H, Sasako M, et al. Randomized clinical trial of adjuvant chemotherapy with intraperitoneal and intravenous cisplatin followed by oral fluorouracil (UFT) in serosa-positive gastric cancer versus curative resection alone: final results of the JCOG trial JCOG9206-2. Gastric Cancer 2011;14:212-8.

56. Miyashiro I, Takachi K, Doki Y, et al. When is curative gastrectomy justified for gastric cancer with positive peritoneal lavage cytology but negative macroscopic peritoneal implant? World J Surg 2005;29:1131-4. 